\title{
MONITORING INTERFACES FASTETHERNET ON CISCO CATALYST 3750 TO ENSURE USE OF THE SECURITY COMPUTER NETWORK IN STTA COMPUTING LABORATORIES
}

\author{
Sudaryanto $^{1}$, Dwi Nurhayati ${ }^{2}$ \\ Program Studi Informatika \\ Sekolah Tinggi Teknologi Adisutjipto \\ J1. Janti, Blok R, Lanud Adisutjipto Yogyakarta \\ Email : ${ }^{1}$ sudaryanto@stta.ac.id, ${ }^{2}$ nrhyt78@gmail.com
}

\begin{abstract}
Cisco is a company that concentrates on hardware and software related to computer networks. One of the hardware produced by Cisco is a switch device that can be used for management of a computer network. Many types of switches that have been produced by Cisco, one of which is the Cisco Catalyst 3750. In the configuration and monitoring of the Cisco Catalyst 3750 user / administrator must do management with command line based configuration. This is because Cisco has not facilitated its users with user interface based configurations. So the user is required to know the code syntax to execute a command on the switch. In this study, researchers will discuss how to create a user interface for monitoring web-based Fastethernet Interfaces on the Cisco Catalist 3750 and use notifications E-mail by utilizing an API to determine the up or down status of a network device. The results of the test show that the application can be monitored by the administrator remotely in real time, the user interface can run well on the personal computer browser and smartphone responsively.
\end{abstract}

Keywords: Port security, monitoring, interfaces ethernet, Cisco Catalyst 3750, API.

\section{Pendahuluan}

Penelitian penelitian sebelumnya banyak membahas tentang manajemen keamanan jaringan baik menggunakan port-port yang tersedia pada switch yaitu : default / static port security, port security dynamic learning, sticky port security [1], dan juga monitoring jaringan dengan menggunakan menggunakan SNMP [2][3], mikrotik [4], sms [5] dan menggunakan web [6] dimana monitoring jaringan mengunakan piranti mikrotik dengan apimikrotik, belum ada penelitian yang memanage dan memonitoring jaringan dengan menggunakan piranti cisco yang melibatkan api-cisco. [7][8] Dalam penelitiannya membahas tentang switch multilayer dan implementasi port security pada sistem keamanan jaringan untuk mengurangi pengguna yang memanfaatkan jaringan Laboratorium Komputasi untuk penggunaan bandwidth di luar perangkat komputer yang telah diijinkan atau didaftarkan, tetapi konfigurasinya masih secara manual yaitu menggunakan command line. Pada penelitian ini peneliti akan membahas tentang bagaimana membuat user interface untuk manajemen Port Security pada Cisco Catalyst 3750 berbasis web sehingga konfigurasi dalam manajemen Port Security Cisco dapat beralih dari konfigurasi command line menjadi konfigurasi berbasis User Interface dan manajemen Catalyst 3750 dapat dilakukan dari mana saja dan kapanpun.

Selain melakukan manajemen peneliti juga akan melakukan monitoring yang merupakan sebuah kegiatan yang bertujuan untuk memantau tentang perubahan status yang ada di suatu perangkat jaringan, sehingga penelitian ini mempunyai tujuan untuk monitoring perangkat Cisco Catalyst 3750 secara real time dari tempat yang berbeda tanpa harus bersentuhan langsung dengan perangkatnya dengan menggunakan web dan notifikasi E-mail 
sebagai monitoringnya. Banyak hal dalam jaringan yang bisa dimonitoring, salah satu diantaranya adalah status up atau down dari sebuah perangkat jaringan.

Adanya sistem manajemen berbasis user interface (web) dan monitoring dapat mempermudah administrator jaringan dalam memantau sistem jaringan yang berada di lapangan dari tempat yang berbeda tanpa harus mengecek secara berkala dan bersentuhan langsung dengan perangkat tersebut.

\section{Metodologi Penelitian}

\subsection{Switch}

Switch merupakan perangkat keras penghubung di dalam jaringan komputer yang lebih banyak digunakan saat ini dibandingkan hub [9]. Hal ini disebabkan karena dengan fungsi yang serupa dengan hub, Switch memiliki dua buah kelebihan utama dibandingkan hub. Kelebihan-kelebihan yang dimiliki oleh switch yaitu:

a. Switch memiliki kemampuan untuk membaca alamat fisik (MAC Address) dari setiap komputer yang terhubung ke dalam switch bersangkutan. Switch menyimpan alamat fisik (MAC Address) dari setiap komputer yang terhubung ke dalam switch tersebut beserta dengan nomor port switch yang digunakan oleh komputer bersangkutan.

b. Switch memiliki kemampuan untuk melakukan filter terhadap paket data yang keluar masuk switch. Hal ini akan memberikan keamanan paket data (terkait dengan pengendusan paket data di dalam jaringan komputer).

Switch bekerja di dua buah layer pada jaringan komputer, yaitu Data Link Layer dan Physical Layer. Pada Data Link Layer, terjadi proses pengecekan terhadap alamat fisik jaringan (MAC Address) untuk otentikasi alamat fisik komputer yang terhubung ke switch, untuk kemudian disesuaikan dengan alamat jaringan pada Network Layer (IP Address). Pada Physical Layer terjadi proses pengolahan sinyal digital.

\subsection{Port Security}

Port Security membatasi jumlah MAC address yang diizinkan terhubung dengan tiap port dan juga dapat membatasi MAC address mana saja yang diizinkan [10][11].

\subsection{Perangkat yang Dipergunakan}

Dalam pembuatan sistem management interfaces ethernet diperlukan hardware dan software yang digunakan sebagai proses penunjang dalam pembuatan sistem management interfaces ethernet.

a. Hardware (perangkat keras) merupakan komponen perangkat yang dapat dilihat secara kasat mata dan dapat disentuh secara fisik. Adapun spesifikasi hardware yang digunakan dalam pembuatan sistem ini, sebagai berikut:

1) Cisco Catalyst 3750

2) Laptop (HP Probook 4321S)

b. Software (perangkat lunak) merupakan komponen yang tidak terkihat secara fisik, tetapi terdapat dalam sebuah komputer.

1) Sistem Operasi Windows 10 Pro

2) Bahasa Pemrograman PHP dan HTML

\subsection{Metode Penelitian}

Pada Gambar 1 dan 2 dijelaskan bahwa administrator bisa melakukan monitoring untuk mengetahui status up atau down dari sebuah perangkat jaringan melalui web dan notifikasi 
email selain itu administrator juga bisa melakukan konfigurasi untuk melakukan perubahan status pada perangkat jaringan dari status up ke down ataupun sebaliknya.

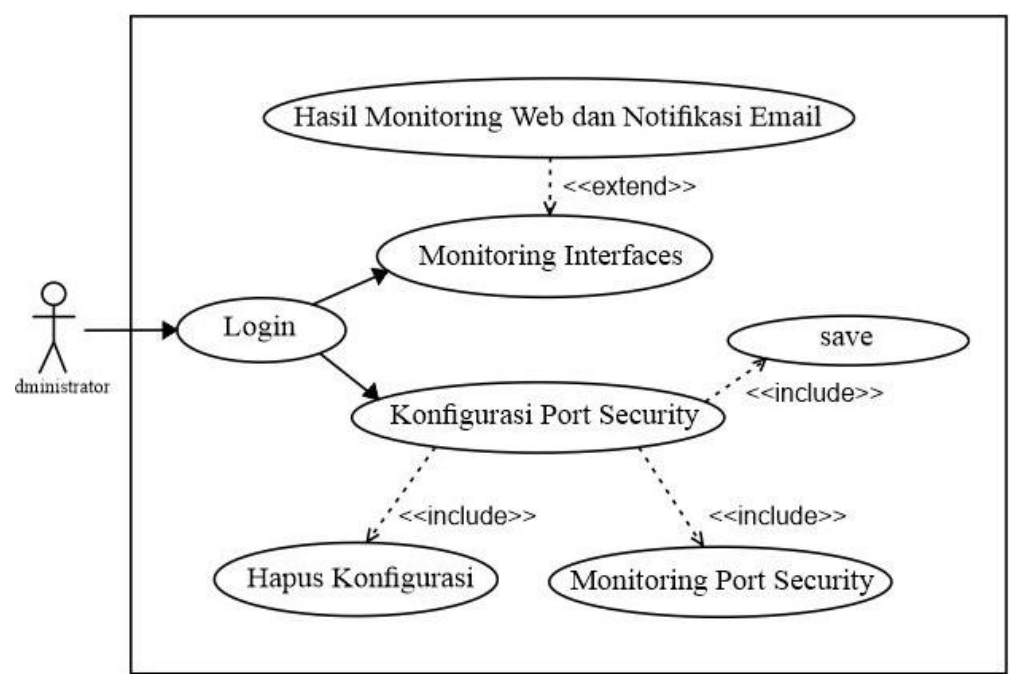

Gambar 1. Use Case Diagram Sistem Management Interfaces Ethernet

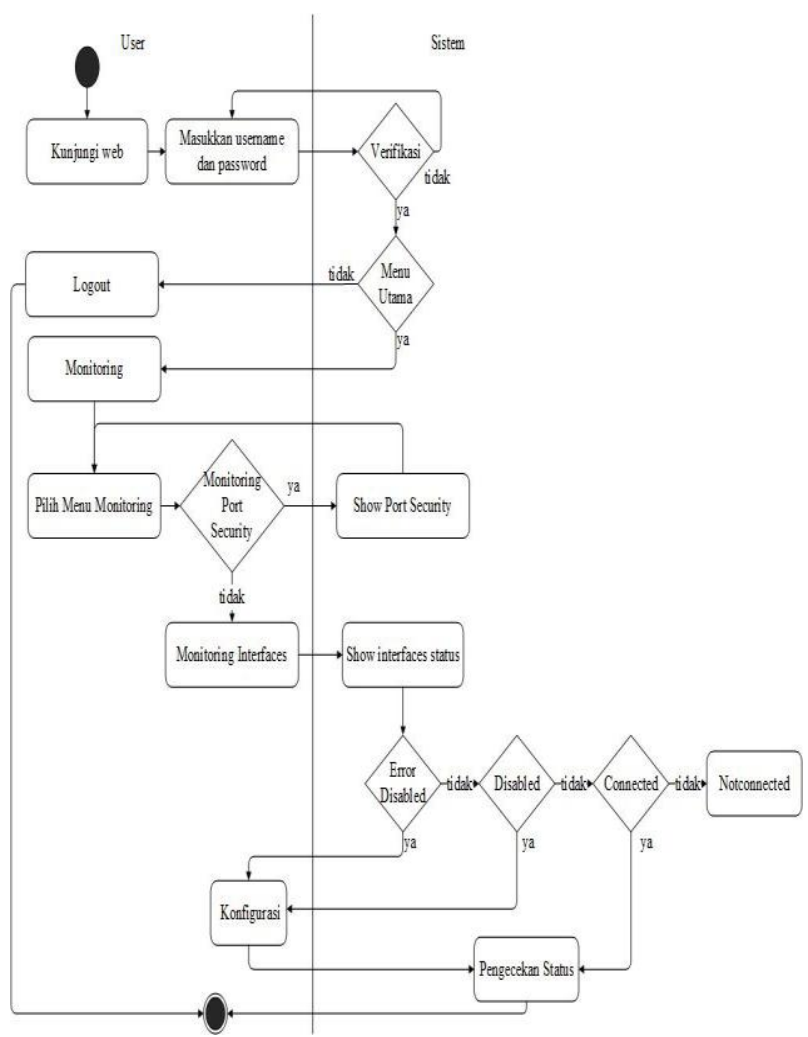

Gambar 2. Activity Diagram Monitoring pada Sistem Management Interfaces Ethernet

\section{Hasil dan Pembahasan}

\subsection{Pengujian interface fasethernet dengan Port Security}

Pengujian dilakukan dengan cara tes ping pada setiap komputer untuk mengetahui balasan dari setiap kondisi. Pengujian dilakukan di laboratorium Komputasi Sekolah Tinggi Teknologi Adisutjipto seperti yang terlihat pada Gambar 3 dan Gambar 4. 


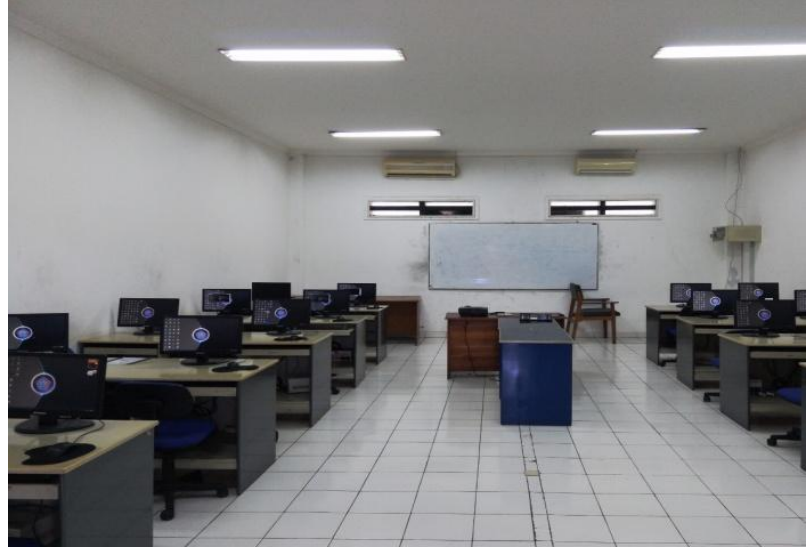

Gambar 3. Laboratorium Komputasi STTA

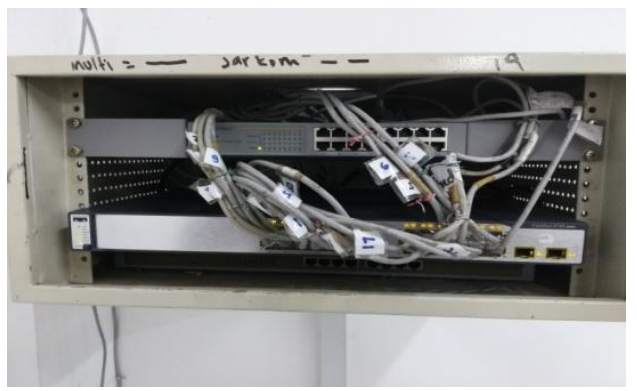

Gambar 4. Switch Cisco Catalyst 3750

Pada pengujian ini, kondisi semua personal komputer belum terkonfigurasi port security dan diulang dengan kondisi semua personal komputer terkonfigurasi port security. Oleh karena itu, jika personal komputer melakukan request atau ping pada semua personal komputer dengan network yang sama maka akan mendapat balasan reply. Proses pengujian (ping) yang terlihat pada Gambar 5 dari personal komputer dengan IP address 10.10.10.1 dan diulang untuk 14 personal komputer yang IP address dan hasilnya dapat dilihat pada Tabel 1.

Tabel 1. Ping antar Komputer Tanpa

dan Dengan Konfigurasi Port Security

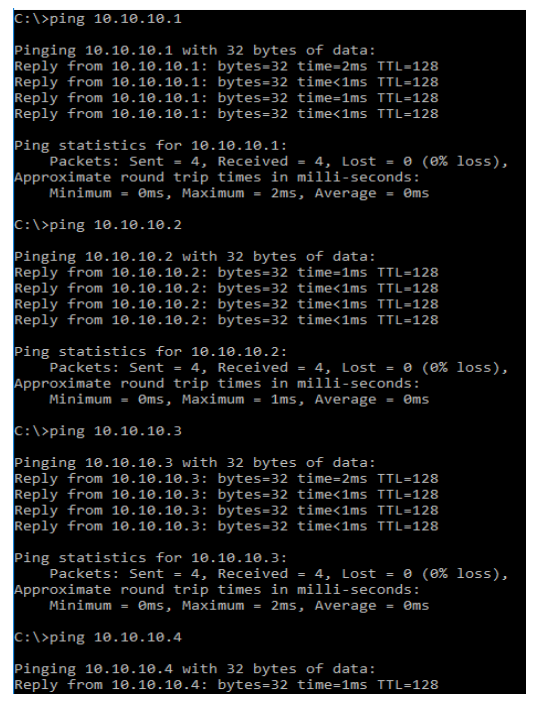

\begin{tabular}{|c|c|c|c|}
\hline No & IP Tujuan & Interface & Hasil \\
\hline 1. & 10.10 .10 .1 & FastEthernet 5/0/1 & $\sqrt{ }$ \\
\hline 2. & 10.10 .10 .2 & FastEthernet 5/0/2 & $\sqrt{ }$ \\
\hline 3. & 10.10 .10 .3 & FastEthernet 5/0/3 & $\sqrt{ }$ \\
\hline 4. & 10.10 .10 .4 & FastEthernet 5/0/4 & $\sqrt{ }$ \\
\hline 5. & 10.10 .10 .5 & FastEthernet 5/0/5 & $\sqrt{ }$ \\
\hline 6. & 10.10 .10 .6 & FastEthernet 5/0/6 & $\sqrt{ }$ \\
\hline 7. & 10.10 .10 .7 & FastEthernet 5/0/7 & $\sqrt{ }$ \\
\hline 8. & 10.10 .10 .8 & FastEthernet 5/0/8 & $\sqrt{ }$ \\
\hline 9. & 10.10 .10 .9 & FastEthernet 5/0/9 & $\sqrt{ }$ \\
\hline 10. & 10.10 .10 .10 & FastEthernet 5/0/10 & $\sqrt{ }$ \\
\hline 11. & 10.10 .10 .11 & FastEthernet 5/0/11 & $\sqrt{ }$ \\
\hline 12. & 10.10 .10 .12 & FastEthernet 5/0/12 & $\sqrt{ }$ \\
\hline 13. & 10.10 .10 .13 & FastEthernet 5/0/13 & $\sqrt{ }$ \\
\hline 14. & 10.10 .10 .14 & FastEthernet 5/0/14 & $\sqrt{ }$ \\
\hline
\end{tabular}

Gambar 5. Tes Ping antar komputer

\subsection{Pengujian hubungan antara komputer setelah ditukar interfacenya}

Pada pengujian ini, komputer yang seharusnya berada di interface FastEthernet 5/0/1 dipindah ke interface FastEthernet 5/0/20 dan begitu juga dengan interface yang lain. Oleh karena itu, jika personal komputer melakukan request atau ping pada semua personal komputer dengan network yang sama maka akan mendapat balasan destination host unreachable sekaligus interface-nya akan otomatis mati (shutdown). Hal ini dikarenakan MAC address yang baru masuk dibandingkan dengan MAC address yang 
ada di switching table pada interface tersebut, jika MAC address-nya berbeda maka action-nya akan dijalankan. Proses pengujian (ping) yang terlihat pada Gambar 6 dari personal komputer(server) dengan IP address 10.10.10.63 dan diulang untuk 14 personal komputer yang IP address dan hasilnya dapat dilihat pada Tabel 2.

Tabel 2. Tes Ping antar Komputer setelah Ditukar Interface-nya

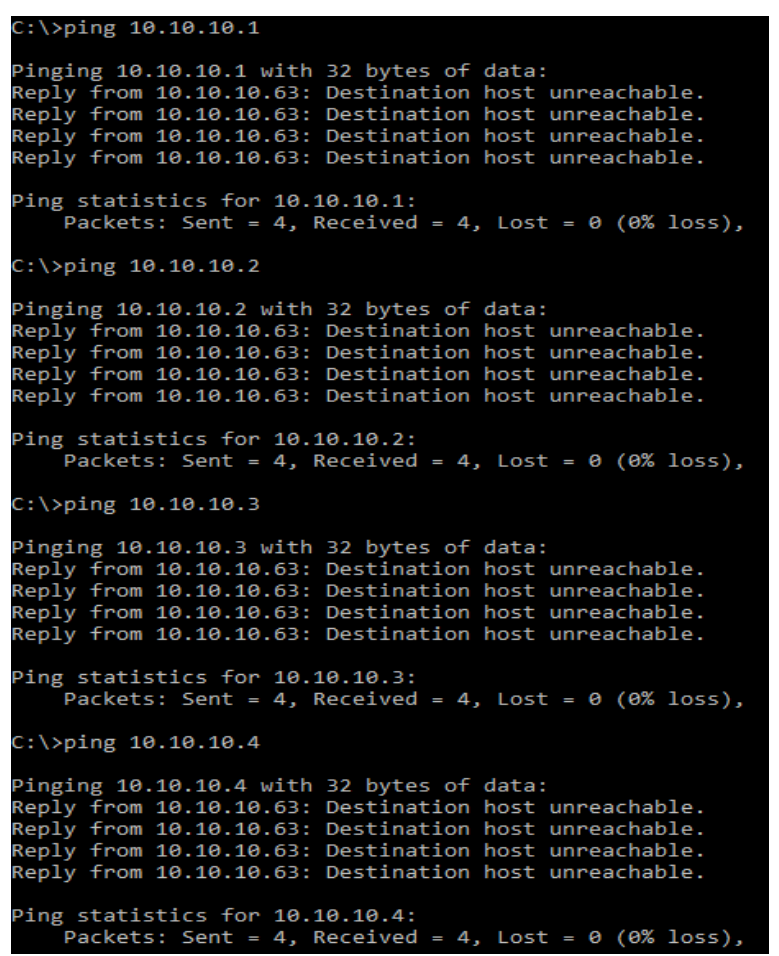

Gambar 6. Tes Ping antar komputer

\begin{tabular}{|c|c|c|c|}
\hline No & IP Tujuan & Interface & Hasil \\
\hline 1. & 10.10 .10 .1 & FastEthernet 5/0/20 & $\mathrm{x}$ \\
\hline 2. & 10.10 .10 .2 & FastEthernet 5/0/19 & $\mathrm{x}$ \\
\hline 3. & 10.10 .10 .3 & FastEthernet 5/0/18 & $\mathrm{x}$ \\
\hline 4. & 10.10 .10 .4 & FastEthernet 5/0/17 & $\mathrm{x}$ \\
\hline 5. & 10.10 .10 .5 & FastEthernet 5/0/16 & $\mathrm{x}$ \\
\hline 6. & 10.10 .10 .6 & FastEthernet 5/0/15 & $\mathrm{x}$ \\
\hline 7. & 10.10 .10 .7 & FastEthernet 5/0/14 & $\mathrm{x}$ \\
\hline 8. & 10.10 .10 .8 & FastEthernet 5/0/13 & $\mathrm{x}$ \\
\hline 9. & 10.10 .10 .9 & FastEthernet 5/0/12 & $\mathrm{x}$ \\
\hline 10. & 10.10 .10 .10 & FastEthernet 5/0/11 & $\mathrm{x}$ \\
\hline 11. & 10.10 .10 .11 & FastEthernet 5/0/10 & $\mathrm{x}$ \\
\hline 12. & 10.10 .10 .12 & FastEthernet 5/0/9 & $\mathrm{x}$ \\
\hline 13. & 10.10 .10 .13 & FastEthernet 5/0/8 & $\mathrm{x}$ \\
\hline 14. & 10.10 .10 .14 & FastEthernet 5/0/7 & $\mathrm{x}$ \\
\hline
\end{tabular}

\subsection{Tampilan Monitoring Interfaces di Sistem Management Interface Ethernet dan di Command Line}

Tampilan monitoring interfaces digunakan untuk melihat status dari setiap interface. Status yang dimaksud dalam sistem ini adalah connected, notconnected, disabled, error disabled. Tampilan monitoring interfaces yang ada di sistem management interfaces ethernet seperti yang terlihat pada Gambar 7 menunjukkan bahwa status connected (warna hijau), notconnected (warna merah), disabled (warna orange), dan error disabled (warna kuning). Sedangkan tampilan yang terlihat pada Gambar 8 merupakan tampilan monitoring interfaces yang ada di command line, jika ingin melihat status dari interfaces maka harus mengetikkan perintahnya terlebih dahulu. 


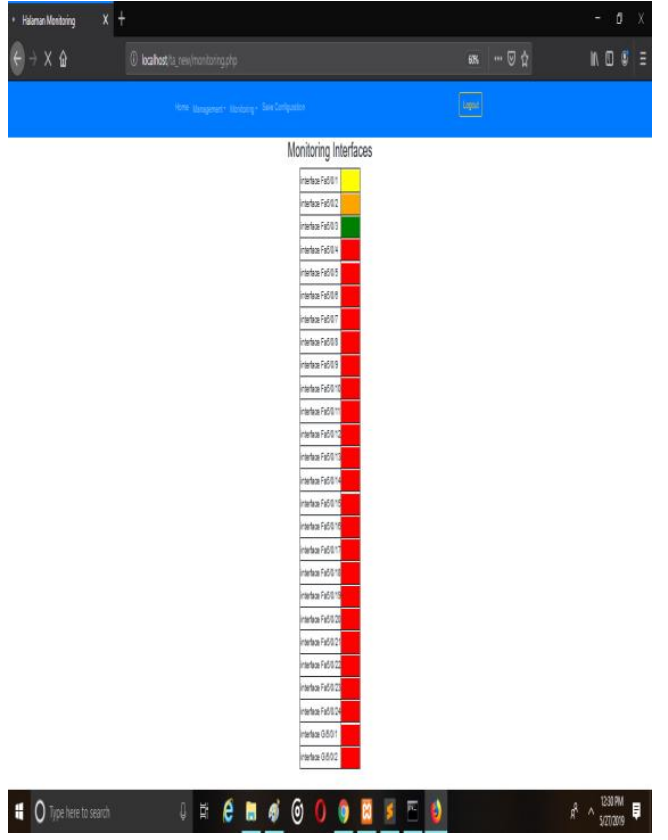

Gambar 7. Tampilan Monitoring Interfaces di Sistem Management Interface Ethernet

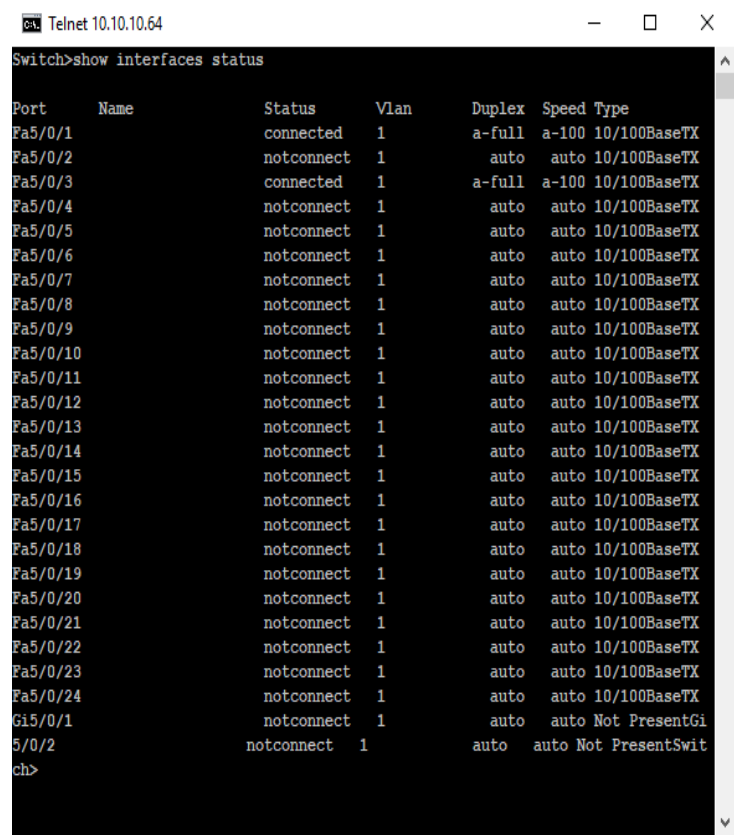

Gambar 8. Tampilan Monitoring Interfaces di Command Line

\subsection{Tampilan Monitoring Port Security di Sistem Management Interface Ethernet dan di Command Line}

Tampilan monitoring port security digunakan untuk melihat status dari interfaces mana saja yang sudah ada konfigurasi port security-nya. Tampilan yang terlihat pada Gambar 9 merupakan tampilan monitoring port security di sistem management interface ethernet. Sedangkan pada Gambar 10 merupakan tampilan monitoring port security di Command Line.
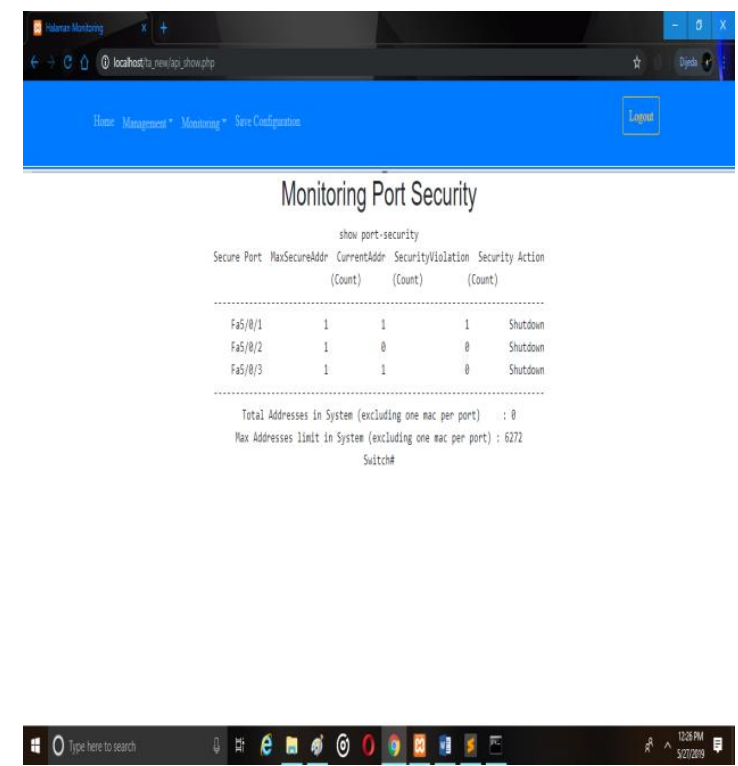

Gambar 9. Tampilan Monitoring Port Security di Sistem Management Interface Ethernet

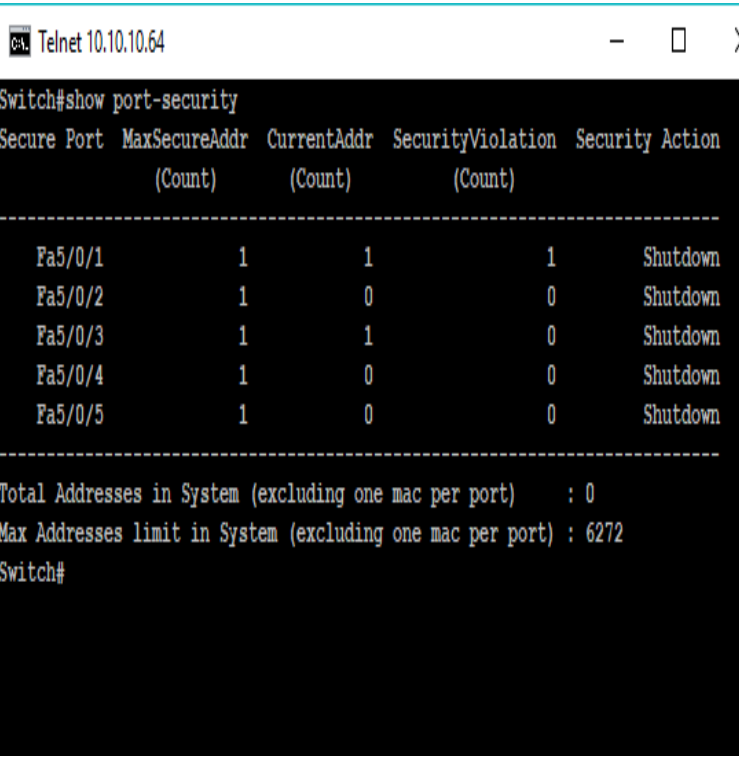

Gambar 10. Tampilan Monitoring Port Security di Command Line 


\subsection{Tampilan Notification pada E-mail}

Notifikasi digunakan untuk memudahkan administrator dalam mengetahui perubahan yang terdapat di dalam perangkat Cisco Catalyst 3750, tampilan notification di Email dapat dilihat pada Gambar 7.

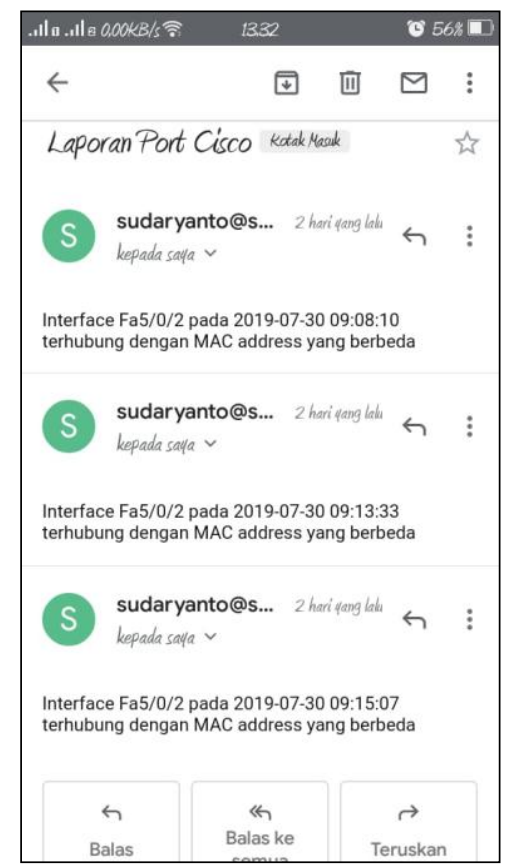

Gambar 7 Tampilan Notification pada Email

Dengan menggunakan monitoring berbasis notifikasi E-mail administrator tidak perlu selalu mengecek secara berkala untuk mengetahui terjadi perubahan aktifitas (status up dan down) ataupun penggunaan port yang tidak diijinkan pada sebuah perangkat jaringan (terhubungnya perangkat komputer dengan perangkat Cisco Catalyst 3750 dimana MAC Address yang ada di perangkat komputer tidak dikenali oleh perangkat Cisco Catalyst 3750) karena apabila terdapat perubahan tersebut maka sistem akan langsung mengirim notifikasi ke E-mail administrator yang sudah diatur dalam program. Selain itu administrator juga tidak perlu datang ke peralatan jaringan untuk memastikan bahwa kondisi peralatan sudah berjalan dengan baik atau tidak karena sudah bisa dilakukan dari jarak jauh secara real time baik konfigurasi port maupun monitoring port interface Fastethernet.

\section{Kesimpulan}

Berdasarkan hasil dari penelitian dengan judul "Monitoring Interfaces Fastethernet On Cisco Catalyst 3750 To Ensure Use Of The Security Computer Network In Stta Computing" maka dapat diambil beberapa kesimpulan sebagai berikut:

a. Berdasarkan uji coba program yang telah dilakukan, didapatkan untuk melakukan konfigurasi dan monitoring administrator tidak perlu bersentuhan langsung dengan perangkat jaringan.

b. Berdasarkan uji coba program yang telah dilakukan, didapatkan bahwa jika terjadi perubahan data di table mac address pada switch port interface Fastethernet maka port akan shutdown. 
c. Berdasarkan uji coba yang telah dilakukan, jika ada perubahan data di table mac address pada switch yang menyebabkan status port Up ataupun Down, sistem akan mengirimkan informasi perubahan ke E-mail yang sudah ditentukan.

\section{Daftar Pustaka}

[1] Sulaiman, K. (2016). Analisis Sistem Keamanan Jaringan Dengan Menggunakan Switch Port Security. CESS (Journal Of Computer Engineering, System And Science) (Vol. 1, ISSN :2502-7131)

[2] Pradikta, R., Affandi, A., \& Setijadi, E. (2013). Rancang Bangun Aplikasi Monitoring Jaringan Dengan Menggunakan Simple Network Management Protocol. Jurnal Teknik Pomits, 2(1), 154-159.

[3] Taftazanie, S., Prasetijo, A. B., \& Widianto, E. D. (2017). Aplikasi Pemantau Perangkat Jaringan Berbasis Web Menggunakan Protokol Snmp Dan Notifikasi SMS. Jurnal Teknologi dan Sistem Komputer, 5(2), 62-68.

[4] Rinaldo, R. (2016). Implementasi Sistem Monitoring Jaringan Menggunakan Microtik Router Os Di Universitas Islam Batik Surakarta. Jurnal Emitor, 16(2), 512.

[5] Gobel. M. A. A., Sumarsono. S., \& Indrianingsih. Y. (2012). Notification Of Security Threats On The Internet Proxy Server Is A Server-Based Short Message Service (SMS). In Compiler STT Adisutjipto Yogyakarta, 1(1), 77-90.

[6] Herliana, A., Rasyid, P.M. (2016). Sistem Informasi Monitoring Pengembangan Software Pada Tahap Development Berbasis Web. Jurnal Informatika, 3(1), 41-50.

[7] Sudaryanto, S. (2018). Implementation Port Security For Security System Network At The Computing Laboratory Of Adisutjipto Technology College. In Conference SENATIK STT Adisutjipto Yogyakarta, 4, 257-265.

[8] Sudaryanto, S. (2018). The Effect Of Multi Layer Switch For Data Transfer Speeds On Computer Network. In Compiler STT Adisutjipto Yogyakarta, 7(2), 85-90.

[9] Pratama, I. P. A. E. (2014). Handbook Jaringan Komputer Teori dan Praktik Berbasiskan Open Source. Informatika. Bandung.

[10] Sofana, I. (2015). Membangun Jaringan Komputer Mudah Membuat Jaringan Komputer (Wire \& Wireless) untuk Pengguna Windows dan Linux. Cetakan Pertama. Informatika. Bandung

[11] Sofana, I. (2012). CISCO CCNP dan Jaringan Komputer (Materi Router, Switch, \& Troubleshooting). Informatika. Bandung.

[12] Sulaiman, O. K. (2016). Analisis Sistem Keamanan Jaringan Dengan Menggunakan Switch Port Security. CESS (Journal Of Computer Engineering, System And Science), 1(1), 9-14. 